\title{
BMJ Open National primary care responses to COVID-19: a rapid review of the literature
}

\author{
Victoria Haldane, ${ }^{1}$ Zhitong Zhang, ${ }^{1}$ Raja Faisal Abbas, ${ }^{1}$ Warren Dodd, ${ }^{2}$ \\ Lincoln L Lau, ${ }^{1,3}$ Michael R Kidd, ${ }^{4,5}$ Katherine Rouleau, ${ }^{5}$ Guanyang Zou, ${ }^{6}$ \\ Zhuo Chao, ${ }^{7}$ Ross E G Upshur, ${ }^{1,5}$ John Walley, ${ }^{8}$ Xiaolin Wei (D) ${ }^{1}$
}

To cite: Haldane V, Zhang Z, Abbas RF, et al. National primary care responses to COVID-19: a rapid review of the literature. BMJ Open 2020;10:e041622. doi:10.1136/ bmjopen-2020-041622

- Prepublication history and supplemental material for this paper are available online. To view these files, please visit the journal online (http://dx.doi. org/10.1136/bmjopen-2020041622).

Received 16 June 2020 Revised 13 November 2020 Accepted 22 November 2020

Check for updates

(c) Author(s) (or their employer(s)) 2020. Re-use permitted under CC BY-NC. No commercial re-use. See rights and permissions. Published by BMJ.

For numbered affiliations see end of article.

Correspondence to

Dr Xiaolin Wei;

xiaolin.wei@utoronto.ca

\section{ABSTRACT}

Objective The aim of this review, conducted in April 2020, is to examine available national primary care guidelines for COVID-19 and to explore the ways in which these guidelines support primary care facilities in responding to the demands of the COVID-19 pandemic.

Design Rapid review and narrative synthesis.

Data sources PubMed, Embase and Google, as well as the websites of relevant national health departments, were searched from 1 January 2020 to 24 April 2020.

Eligibility criteria Documents included must be issued by a national health authority, must be specific to COVID-19 care, directed at healthcare workers or managers, and must refer to the role of primary care in the COVID-19 response.

Results We identified 17 documents from 14 countries. An adapted framework on primary care challenges and responses to pandemic influenza framed our analysis. Guidelines generally reported on COVID-19 service delivery and mostly made specific recommendations for ensuring continued delivery of essential primary care services through telehealth or other virtual care modalities. Few offered guidance to support surveillance as a public health function. All offered guidance on implementing outbreak control measures, largely through flexible and coordinated organisational models with partners from various sectors. There was a lack of guidance to support supply chain management and practice resilience in primary care, and lack of personal protective equipment represents a serious threat to the provision of quality care during the pandemic. Conclusions Current national primary care guidelines for COVID-19 provide guidance on infection control and minimising the risk of spread in primary care practices, while supporting the use of new technology and coordinated partnerships. However, to ensure primary care practice resilience and quality of care are upheld, guidelines must offer recommendations on supply chain management and operational continuity, supported by adequate resources.

\section{INTRODUCTION}

Primary care focuses on medical care and is the provision of integrated, accessible healthcare services by clinicians who are accountable for addressing a large majority of personal healthcare needs, developing a sustained partnership with patients, and practising in the context of family and community.

\section{Strengths and limitations of this study}

This is the first rapid review, to our knowledge, to examine national guidelines for COVID-19 treatment and management in primary care.

- This review includes both English-language and Chinese literature and thus we may miss key regions based on other languages.

- We have included guidelines from a diverse range of countries to compare global approaches to COVID-19 guidelines for primary care.

- The review relies on grey literature to capture national guidelines as there is a lack of academic literature on primary care guidelines for COVID-19.

In keeping with the commitments of the Declaration of Astana and of the political declaration on Universal Health Coverage, primary care services, as a foundational and central element of robust health systems, are at risk of being overwhelmed by the current COVID-19 pandemic. ${ }^{2-4}$ Primary care settings are, in many places, patients' closest and first point of contact with the health system. In the early months of 2020 we have seen tremendous pressure placed on healthcare systems as a result of the pandemic. Countries worldwide have responded to these demands, and prepared for future waves, by rapidly building up dedicated tertiary care facilities and other treatment centres. However, some health systems may not be equipped to quickly increase hospital and health workforce capacity. Thus, in both high-income and low-income and middle-income countries (LMICs), primary care is poised to become increasingly crucial in the COVID-19 response as secondary and tertiary hospitals are strained by patients requiring intensive management. ${ }^{5}$ Primary care is key to wellfunctioning health systems, and has played an important role in managing patients and implementing pandemic policies during the $2009 / \mathrm{A} / \mathrm{H} 1 \mathrm{~N} 1$ pandemic. ${ }^{6}$ Indeed, the 'primary care safety net' has been described as 
key to treating underserved populations and to providing surge capacity in such circumstances. ${ }^{7}$

As the onset of COVID-19 is hallmarked by mild to moderate symptoms during which individuals are infectious, primary care has a crucial role in the prevention, triage, diagnosis and management of patients in the community. Robust and comprehensive guidelines are needed to support primary care response during pandemics. ${ }^{8}$ Indeed, primary care has been previously identified as providing key public health functions, including health protection and promotion, disease prevention, community-based screening and testing surveillance and response, as well as emergency preparedness. ${ }^{9}$ However, current guidelines are heterogeneous and span care provided in primary care, home care as well as isolation guidance. Given that the main benefit of guidelines is to improve quality of care received by patients, there is a need for rapid research and synthesis to inform creation of guidelines that support primary care providers in delivery of quality care during the pandemic. ${ }^{10}$ The aim of this review is to examine available national primary care guidelines for COVID-19 and to explore the ways in which these guidelines support primary care facilities in responding to the demands of the COVID-19 pandemic.

\section{METHODS}

In light of the rapidly evolving situation, policy makers require evidence synthesis to produce robust guidance for primary care providers. The WHO recommends the use of rapid reviews to provide such evidence. ${ }^{11} \mathrm{We}$ conducted a rapid document review with a qualitative analytical approach to allow for narrative synthesis of the data. ${ }^{12}$

Our review is informed by an adapted framework outlining primary care challenges and responses to pandemic influenza (table 1) ${ }^{13}$ The framework outlines four key domains: clinical service delivery, public health functions of primary care facilities, operational level functions at the primary care facility and the health systems level factors-all of which may act as barriers to or facilitators of care provision.

\section{Information sources and search}

To identify relevant documents we searched PubMed, Embase and Google, as well as the websites of relevant national health departments, such as the ministries of health or public health, or centres for disease control. We searched guidelines from 1 January 2020 to 24 April 2020. We applied the following standard Boolean phrase during the searches: ('COVID 19' AND 'guidelines' AND 'ministry of health' OR 'centres for disease control' AND country name). We also searched references of the selected relevant policy documents for additional related information. We consider guidelines to be documents issued by national authorities within countries that communicate the intention of that national authority as to how COVID-19 should be diagnosed,

Table 1 Adapted framework of primary care challenges and response to pandemic influenza

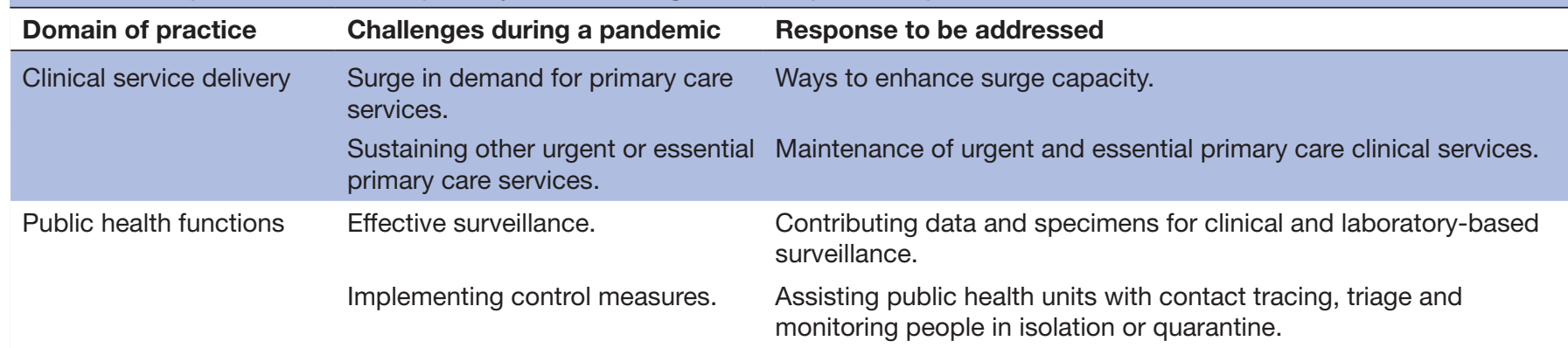

\begin{tabular}{|c|c|c|}
\hline \multirow[t]{3}{*}{$\begin{array}{l}\text { Primary care facility } \\
\text { operational level }\end{array}$} & $\begin{array}{l}\text { Minimising the risk of COVID-19 } \\
\text { spread in the practice setting. }\end{array}$ & $\begin{array}{l}\text { Structuring clinical facilities and stockpiling personal protective } \\
\text { equipment to enable effective infection control. }\end{array}$ \\
\hline & Access to medications. & $\begin{array}{l}\text { Reliable delivery of medications and essential equipment to the } \\
\text { practice. }\end{array}$ \\
\hline & $\begin{array}{l}\text { Ongoing communications with } \\
\text { patients, public health and the } \\
\text { health system. }\end{array}$ & Strengthening capacity of communication systems. \\
\hline \multirow[t]{2}{*}{ Health system level } & $\begin{array}{l}\text { Overall organisation of the health } \\
\text { system. }\end{array}$ & $\begin{array}{l}\text { Integrated planning across the health system, for example, with } \\
\text { other primary care facilities, ambulatory care services, public health } \\
\text { units and hospitals. }\end{array}$ \\
\hline & & $\begin{array}{l}\text { Appropriate legislation, for example, to address professional } \\
\text { accreditation, indemnity and ethical concerns. }\end{array}$ \\
\hline
\end{tabular}

Adapted from Patel et al. ${ }^{13}$ 
treated and managed in a primary care setting. We attempted to ensure global representation by searching for countries with publicly available English-language or Chinese-language documentation from across the WHO regional groups. We began with countries that had experienced community transmission of COVID-19 before our search date, with the assumption that these countries would have primary care guidance available. If not available, we then examined countries with COVID-19 cases identified before our search date, to identify English-language or Chinese-language national guidance on primary care.

\section{Inclusion criteria}

To be included in our review, the document must be issued by a national health authority (Ministry of Health, National Centre for Disease Control and so on), must be specific to COVID-19 care, directed at healthcare workers or managers, and must refer to the role of primary care in the COVID-19 response. If the documents were published in series, the most recent version was considered. We chose countries from each of the six WHO regions in order to aim for geographical diversity. Countries were chosen based on their number of reported cases, with oversampling of countries with higher reported case numbers, as well as the availability of English-language or Chinese-language documents.

\section{Study selection and data charting}

Two reviewers screened titles, abstracts and full text against the inclusion criteria. This process followed the Preferred Reporting Items for Systematic Reviews and Meta-Analyses (PRISMA) four-stage process (identification, screening, eligibility and final inclusion). Disagreements were resolved through discussion between the two reviewers. At the time of study selection, no national guidelines meeting our criteria were available through PubMed or Embase; thus, our review relies on grey literature from national sources available in the English or Chinese language. One reviewer charted data from eligible guidance using a standardised Microsoft Excel form developed for this study based on our conceptual framework; this was reviewed by another reviewer.

\section{Analysis procedures}

Data were analysed using elements of both content analysis and the framework method using the conceptual framework above to guide analysis. ${ }^{14} 15$ We conducted a descriptive summary of the characteristics of included documents. We provide a narrative synthesis of the ways in which selected countries are addressing the domains of primary care practice as per our framework.

\section{Patient and public involvement}

We did not directly involve patients or the public in the conceptualisation of this study.
RESULTS

We identified 17 documents from the grey literature which comprised national COVID-19 guidelines. Of these 11 were general national guidelines for COVID-19 which referred to primary care within the text, 5 were specific to primary care and 3 had primary care as a specific subsection. Figure 1 shows the PRISMA diagram of our results. Online supplemental material 1 provides an overview of these documents. At the time of the study search, documents meeting our study criteria were found from China, Malaysia, the Philippines, New Zealand, Australia, Canada, USA, UK, Ireland, Ethiopia, Nigeria, South Africa, Sri Lanka and India. Online supplemental material 2 provides a summary of our results.

In table 2 we present an overview of the key framework domains and the corresponding response indicators for each country. Our results show that all national primary care guidelines included information on control measures, ways to minimise risk of spread and communication mechanisms. The majority of national guidelines also referred to integrated planning mechanisms for primary care. Fewer national guidelines reported on aspects of clinical service delivery in primary care, with only half of the countries offering guidance on surge capacity. Only 4 of 14 countries' guidance described access to medication considerations, and fewer described legislative or financing considerations to support primary care. Only national guidance from Canada covered all domains.

\section{Clinical service delivery}

Guidelines from the Philippines, China, Canada, USA, UK and Ethiopia described recommendations to manage surge capacity in primary care facilities during the COVID-19 pandemic. Guidelines from the Philippines and the UK provided guidance on the care of common (eg, respiratory) infectious diseases in the context of COVID-19, and described the reorganising of existing primary care networks to ensure collective capacity within the health system. The Philippines guidelines called on local government units to organise existing healthcare provider networks across the public and private sector to optimise the COVID-19 model of care. ${ }^{16}$ The UK guidance asked practices to work with their Clinical Commissioning Group to create regional models of care that suit their context. ${ }^{17}$ Guidance from China described prioritising staff, medicines and personal protective equipment (PPE) for designated township hospitals (the site of primary care in China), but also capacity-building the workforce system-wide through technical training to ensure surges can be effectively managed. ${ }^{18} 19$ The US guidance highlighted that planning for a surge in patients with respiratory infection should be a primary goal of health facilities. ${ }^{20}$ However, the document did not outline recommendations for action beyond ensuring adequate staffing. This is similar to guidance from Ethiopia, which encouraged providers to allow for expanded service hours when needed to ensure access to care during surges. ${ }^{21}$ 


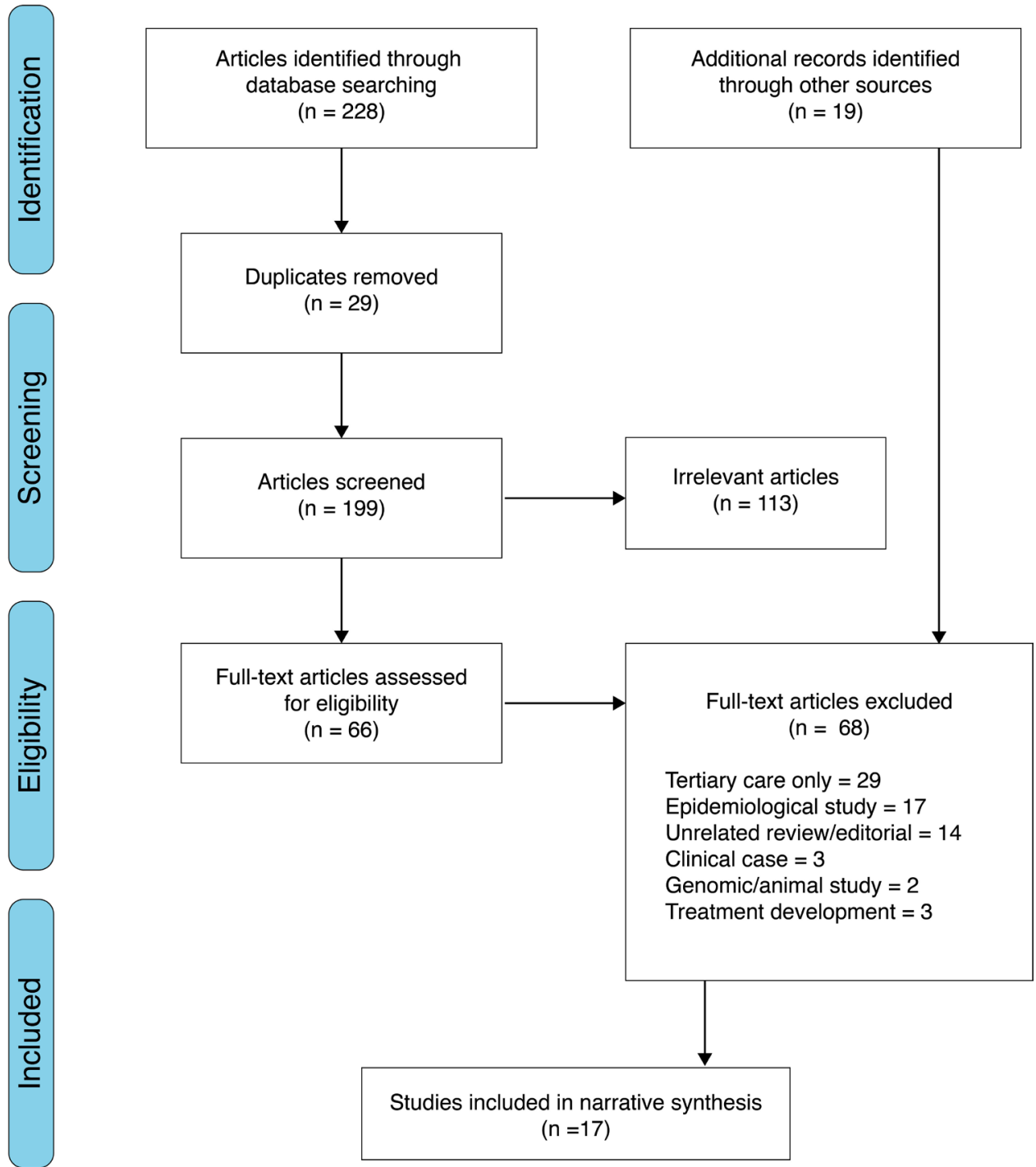

Figure 1 PRISMA diagram. PRISMA, Preferred Reporting Items for Systematic Reviews and Meta-Analyses.

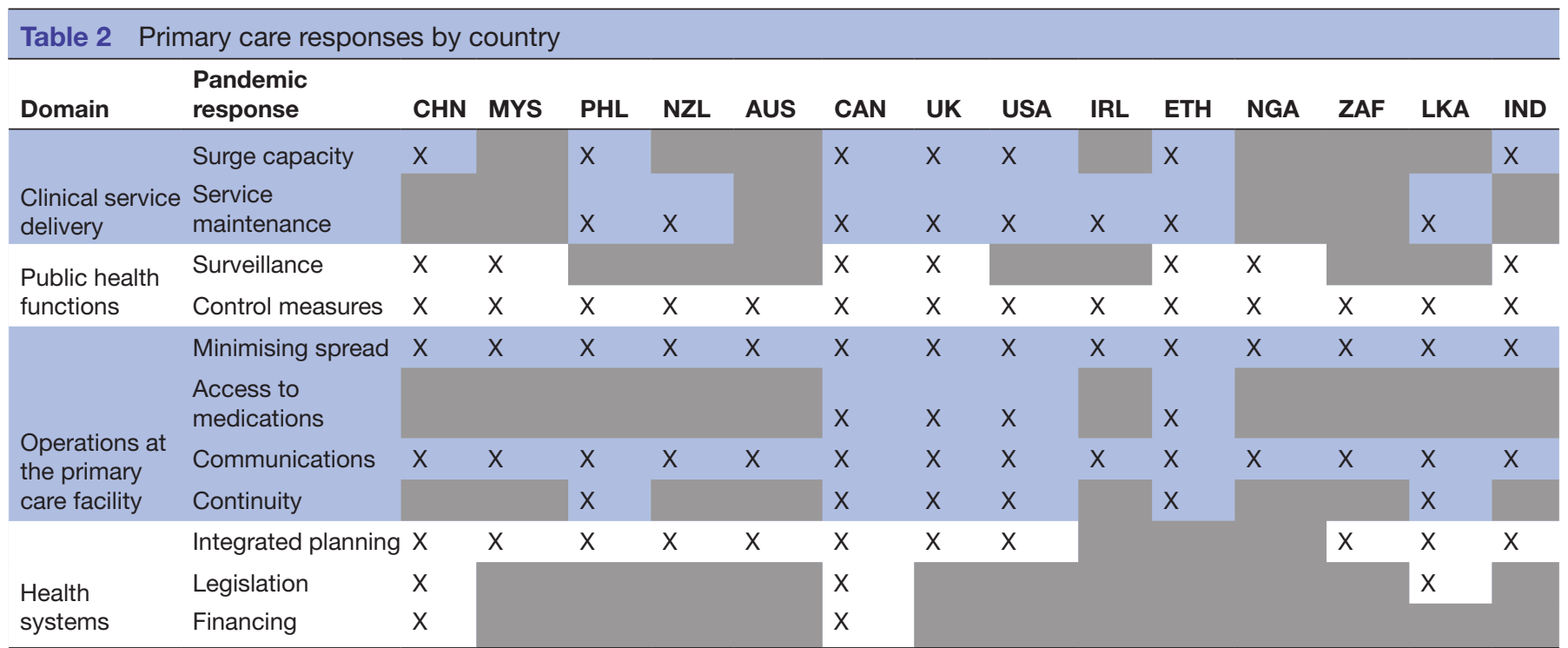

AUS, Australia; CAN, Canada; CHN, China; ETH, Ethiopia; IND, India; IRL, Ireland; LKA, Sri Lanka; MYS, Malaysia; NGA, Nigeria; NZL, New Zealand; $\mathrm{PHL}$, the Philippines; ZAF, South Africa. 
Canadian guidance expanded on this and described the need for surge capacity planning to ensure there is additional equipment and staff to meet demand and prevent burn-out. The guidance included strategies that provinces and territories can adopt to enhance primary care surge capacity as well as steps practices can take to manage patient demand on care; and outlined an overall health system risk management approach including the scenario in which primary care services are 'faced with an overwhelming volume of patients'. ${ }^{22}$

Few jurisdictions in our review recommended care for persons with COVID-19 in the community (primary care-supported home care) as an overarching national approach and thus few guidelines described the ways in which primary care service delivery should encompass the care of individuals with COVID-19. The US guidance described how primary care providers should arrange for a healthcare worker to check in with patients under home care for COVID-19 through telephone or patient portals. ${ }^{20}$ New Zealand guidance described how the provision of active monitoring of non-hospitalised probable and confirmed cases is the responsibility of the public health unit unless there has been clear delegation to another provider. ${ }^{23}$

Guidance from Canada, Ireland, UK, Sri Lanka and Ethiopia described the maintenance of urgent and essential primary care clinical services. The majority of these recommended the use of remote consultations offered via telehealth. ${ }^{172122} 24$ Guidance from Canada also outlined the need to ensure continuity of time-sensitive essential services, such as contraception, abortion, testing for sexually transmitted infections and selected immunisations, as well as the need for providers to track deferred services for later follow-up. ${ }^{22}$ Guidelines from Ethiopia similarly called for referral or deferral plans for patients who do not need acute care. ${ }^{21}$ Guidance from the UK described the potential to use dedicated home visits for those patients at high risk for severe COVID-19 infection. ${ }^{17}$ The guidance also described the need for mental health and psychological well-being services in primary care, as well as advanced care planning and palliative care services.

\section{Public health functions}

Guidelines from China, Canada, Malaysia, Ethiopia, Nigeria and India offered information on the ways in which primary care facilities can support surveillance activities. ${ }^{1921} 2225-28$ Surveillance activities, as per our framework definition, may be broadly categorised as the provision of biological samples or data to public health units as part of larger active surveillance activities. No guidance in our selected documents described the collection of biological samples. Guidance from China, Malaysia, Ethiopia and India described a process whereby primary care would collect information of suspected individuals and transmit this information to public health teams for further investigation. ${ }^{18} 212527$ Guidance from Nigeria recommended that providers should maintain a screening register of patients. ${ }^{26}$ Both Canadian and Australian guidelines highlighted that local public health units are responsible for reporting COVID-19 cases to provincial, territorial or state public health authorities. ${ }^{29}{ }^{30}$ Guidance from India described the role of community health workers who have been mobilised to support contact tracing. ${ }^{27}$

Most guidance outlined steps towards the implementation of control measures within primary care facilities. Guidance from the Philippines, Sri Lanka, USA, Ireland and UK specifically described a process which included phone-based triage. ${ }^{16} 17202431$ In the Philippines, Sri Lanka, Ireland and UK, patients reporting symptoms of COVID-19 over the phone would be triaged to designated COVID-19 assessment or treatment sites for further investigation. ${ }^{16} 171$ In the UK (NHS 111) and the USA, patients would be triaged/diagnosed over the phone to determine whether they can be presumed to be COVID19-positive and advised to remain at home and selfmonitor. ${ }^{17}$ Guidance from Canada, Malaysia, South Africa and Ethiopia described the role of primary care facilities in screening, triage and referral. ${ }^{2122} 252932$ Guidance from the UK, Ireland, USA, China, Malaysia and Nigeria also specifically highlighted the need for patient screening from first contact at the clinic through observation of symptoms by all clinic staff and receptionist screening through questions. ${ }^{171920252631}$

\section{Primary care facility operational level}

At the primary care facility level, guidance from all included countries offered recommendations for minimising the spread of infection within primary care facilities through strategies to minimise contact, rigorous infection prevention and control procedures, and the use of PPE. Guidance from the Philippines and Sri Lanka recommended telemedicine to minimise contact, while guidance from Ireland suggested offering dedicated clinic hours to see symptomatic patients and to schedule these appointments in succession. ${ }^{162431}$ Nigeria similarly recommended that healthcare facilities bundle care activities to minimise exposure to symptomatic patients. ${ }^{33}$ Guidance from Canada, USA, Ireland, UK, Australia, Sri Lanka, Malaysia, South Africa and Nigeria described the need to ensure physical distancing within primary care facilities and the need to set up dedicated areas for patients with symptoms of COVID-19. ${ }^{17} 2022242530-33$ Guidance from the USA, Ireland, New Zealand, Australia, Sri Lanka and South Africa specifically recommended providing symptomatic patients with a disposable surgical mask on entry to the clinic. All guidance reported on the need for staff PPE complemented with frequent hand washing and avoiding touching one's face. Guidance from Sri Lanka described clothing choices (wearing short sleeves) and personal grooming measures (keeping themselves cleanshaven and tying their hair back) to support the use of PPE and appropriate hygiene. ${ }^{24}$ Canadian guidelines provided advice on the reprocessing of N95 respirators by staff. ${ }^{29}$

Guidance from Canada, USA, UK and Ethiopia described measures to ensure that patients had 
uninterrupted access to medications. ${ }^{17}$ 20-22 Guidance from Ethiopia recommended facilities develop plans to expedite medication refills. ${ }^{21}$ Guidance from the USA encouraged providers to reach out to high-risk patients and ensure they have sufficient medication. ${ }^{20}$ Guidance from the UK advised practices not to increase repeat prescriptions so as to reduce supply chain pressure to deliver multiple months' worth of medications in a short time span. ${ }^{17}$ Further, the guidance made an urgent request for practices to change their policies and ensure they accept repeat prescription orders online through the practice website, to support population-level physical distancing policies. Guidance from Canada encouraged practices to implement a system for prescription renewal that does not require inperson visits, as well as to be flexible in allowing patients to stock up on opioid agonist treatments and medication to manage chronic pain. ${ }^{22}$ Canadian guidance was unique in offering information on supply chain issues and management, as well as prevention and mitigation strategies.

All guidance reported methods of telephone communication with the wider health system either as part of telephone triage or referral to onward tertiary care. Beyond the health system, guidance from the UK described an online system linking the National Health Service (NHS) and the Department for Work and Pensions to ensure acceptance of digital isolation ('sick') notes. ${ }^{17}$ Guidance from China, Canada, USA, Ireland and UK specifically described the use of telecommunications technology to ensure ongoing service delivery. ${ }^{1719202231}$ Guidance from China reported the use of smartphone apps to connect with patients, as well as to ensure communication between the health system and community groups mobilised to respond to the pandemic. ${ }^{19}$ Guidance from the UK (NHS COVID-19) included online guidance and self-assessment, while Canada called for the development of online tools for self-assessment and self-monitoring in different languages. ${ }^{22}$

Guidance from the Philippines, China, Canada, USA, UK and Ethiopia reported on strategies to ensure operational continuity of primary care facilities. Guidelines from the Philippines and Ethiopia recommended the creation of staffing plans to address potential human resource shortages. ${ }^{1621}$ Guidelines from the USA encouraged individual practices to plan for absenteeism through cross-training of current employees, extending hours or hiring temporary employees. ${ }^{20}$ Guidance from Canada, China and UK encouraged cross-organisational collaboration to maximise clinical capacity through relocation of staff or services based on skills, needs and available training. 171922

\section{Health system level}

All guidance referred to some form of integrated planning across the health system, most commonly this was through the triage, notification or referral processes. Guidance from the Philippines described coordination between the Department of Health and local government units to form province-wide or city-wide health systems incorporating private and public sector care in order to respond to SARS-CoV-2. ${ }^{16}$ Guidance from the UK encouraged primary care practices to engage with research programmes, work with community pharmacy and community services, and provide non-medical support through collaboration with social prescribing link workers, who provide connections to community groups and statutory services for practical and emotional support. ${ }^{1734}$ Guidance from China reported on the need to mobilise different organisations to improve case finding including all levels of healthcare facilities, local governments, community organisations and employers to support the pandemic response. ${ }^{19}$ This was facilitated by a call for improved data sharing among different departments through regular meetings and working groups. From a grassroots perspective, guidance from India encouraged community health workers to create a supportive local environment by talking to local influencers, planning community support for high-risk groups, developing community networks for support, and helping develop community household emergency contact lists. ${ }^{27}$ In the USA, guidance encouraged primary practices to engage local community service organisations and home health services to assist home care patients with delivery of food, medication and other goods. ${ }^{20}$

National guidelines from Sri Lanka, China and Canada described legislation. ${ }^{19} 22{ }^{24}$ Guidance from Sri Lanka called for primary care providers to seek police or legal support in accordance with the Quarantine Law for patients who refused to be admitted to hospital or undertake home isolation. ${ }^{24}$ In the guidance from China this included an explanation of policies which grade each county based on the level of risk of COVID-19 outbreak and tailoring interventions and controls according to the risk level. ${ }^{19}$ Guidelines from Canada included a section on the legal considerations that may arise during the provision of COVID-19 healthcare and denote action for federal, provincial/territorial governments as well as regulatory authorities and healthcare organisations to support the pandemic response. ${ }^{22}$ From a financing perspective, guidance from China asked local governments to commit funding and materials, such as PPE and medical supplies, towards COVID-19 prevention and control. ${ }^{19}$ The Canadian guidelines called for provinces and territories to establish new billing fee codes for virtual consultations and telephone prescribing. ${ }^{22}$

\section{DISCUSSION}

The primary goal of clinical guidelines is to help improve quality of care. ${ }^{10}$ Our rapid review findings highlight strengths, opportunities and gaps in COVID-19 national guidelines for primary care published in early 2020. The strengths of available national guidelines include clear and robust guidance on control measures, minimising the risk of spread and communication between primary care and other health system actors. Opportunities to 
support primary care facilities include the use of telehealth to support guidance on surge capacity, ensuring service maintenance and supporting integrated planning. To address gaps in national guidance, there is a need for strengthened guidance on access to medication, ensuring operational continuity of primary care facilities and research on optimal configuration of primary care services for a resilient response. This review also underscores the need to ensure a safe working environment through appropriate PPE resource allocation.

Our review found that telehealth plays a key role in national guidelines for COVID-19 and offered a way to provide clinical service delivery and public health functions in primary care. Importantly, countries such as Canada have made clear in national guidance the financial mechanisms available to bill for primary care telehealth services. ${ }^{22}$ Others, such as Australia, have provided similar mechanisms; however, these are not explicitly included in national guidelines. ${ }^{35}$ Telehealth has the potential to provide accessible, comprehensive and continuous care for both patients with COVID-19 and those requiring routine care for other health needs, including psychosocial well-being needs; however, caution is warranted in viewing technological solutions as a panacea to all patient groups given the known challenges to access in under-resourced settings and to underserved populations. ${ }^{36}$ Health systems will also face structural challenges to scaling and sustaining telehealth, as well as ensuring onward linkage to care, as demand outpaces capacity. For example, the telehealth network in Ontario, Canada experienced a day-long shutdown due to technical issues after media coverage on telehealth screening. ${ }^{37}$ In addition, many primary care clinics in LMICs may not have sufficient health information systems, internet connection and online payment options to effectively operate telehealth. As models of telehealth are developed, they should be clearly communicated in national guidelines.

Our findings also show movement at the primary care facility level and the health system level towards flexible and coordinated organisational models to support service delivery and, to a lesser extent, public health functions. Available guidelines require primary care to deliver a range of COVID-19 services, including screening and assessment, home care and discharge support, as well as attend to the ongoing routine care needs of patients. Most of the reviewed primary care guidelines relied on referral to special centres or dedicated hospitals for public health functions such as testing and tracing. To achieve service delivery goals and ensure integration with public health units, guidelines report on establishing partnerships through existing or newly formed networks of primary care facilities and other health system actors, including both public and private sectors. While national guidelines from the Philippines specifically refer to partnerships with the private sector, there have been other examples of coordination with the private sector to strengthen health system capacity for triage in primary care. Public health preparedness clinics in Singapore and respiratory clinics in Australia, which actively involve private primary care practices in the COVID-19 response, are a promising model to build capacity for triage in primary care. ${ }^{38} 39$ Private care partnerships have previously proven promising in providing quality care for tuberculosis in LMICs. ${ }^{40}{ }^{41}$ These activities support and strengthen community-oriented primary care. In community-oriented primary care, primary clinical care for individuals and families is provided with special attention to continuity of care and includes a focus on the demographics and needs of the community as a whole in planning, delivering and evaluating care. ${ }^{42}$ However, coordinated and flexible organisational models will be challenged by pre-existing health system fragmentation. Countries will need to actively strengthen linkages between primary care and public health units to support a robust trace, test, isolate and support response to COVID-19. Further, the connection between primary and secondary care must be also strengthened to ensure that guideline recommendations can be consistently followed, even during surges.

National guidance from the USA and other countries additionally calls for links to community and social service organisation to support patients during quarantine or self-isolation. Community partnerships with nongovernmental organisations (NGOs) and faith-based organisations for patient support are foundational to other infectious disease programmes such as tuberculosis and HIV and have shown to be beneficial in pandemic influenza preparedness. ${ }^{9}{ }^{43-45}$ As many LMICs rely on community health workers, community organisations and NGOs for routine service delivery, this presents an opportunity to scale up the available resource pool for coordinated and comprehensive primary care. To support such initiatives, there is a need for inclusion of guidance on best practices for establishing flexible organisational models which bridge often poorly connected or separate sectors, including health, social services, faith organisations and the private sector. This guidance must provide recommendations that are supported by financial and training resources to provide coordinated and quality care, while ensuring fair and safe work for those in these roles.

Underpinning these efforts and opportunities, however, is the critical worldwide shortage of medical products, including PPE and COVID-19 testing kits, which poses a direct risk to healthcare workers, community organisation support workers, patients and their families. ${ }^{46} 47$ Findings from our review show guidelines clearly report the need for primary care workers to use PPE in order to provide safe and quality care for patients with COVID-19; however, the scale of the pandemic is placing unprecedented demands on these resources. As our findings show, health systems globally are scaling up their health workforce and coverage through retraining of non-practising health workers or partnerships with private providers and community organisations. This capacity will be directly threatened by the ongoing shortage of PPE and medical 
supplies, given not only the requirement of PPE for safe working conditions but also that many providers have stated they will not work without adequate PPE. Further, many primary care settings lack the necessary procurement linkages to ensure an ongoing supply of PPE and resources. ${ }^{4-50}$ Without significant investment and support of mass production of PPE, and complementary supply chain support to ensure distribution, these shortages pose a serious threat to our ability to protect healthcare workers while safely providing comprehensive services to persons seeking care for COVID-19. There is a pressing need to provide guidance on supply chain management and operational continuity recommendations to ensure what UK NHS guidelines refer to as 'practice resilience' in primary care.

The pandemic has exposed weaknesses in health systems worldwide, and countries are using guidelines to communicate important response measures to front-line workers. As health systems implement strategies, reconfigure models of care and pivot towards technology, there is also an urgent need for research on optimal configurations of primary care services for resilient response.

\section{Limitations}

Given the lack of published literature to date on primary care guidelines or interventions for COVID-19, and the speed at which information is changing as experts adjust to evolving knowledge, this review relied on grey literature. As such, our review is at risk of sampling bias from our search strategy and selected materials; however, we have aimed to conduct a thorough grey literature search for publicly available guidelines. Our study may also be limited by our choice of framework analysis, which may have limited our ability to assess relative strengths and weaknesses of national guidance. A further limitation is that our analysis only includes guidelines published in the English or Chinese language and thus we miss key regions. However, we did search for English guidelines in all WHO regions beginning with countries with the highest reported cases. Finally, our review was conducted with guidelines made publicly available up to April 2020. However, we believe that our review provides important and enduring information for primary care in response to the ongoing COVID-19 pandemic.

\section{CONCLUSION}

Primary care is central to providing quality care for the usual common infections and now also for COVID-19, while also undertaking important public health functions. Appropriate, evidence-based guidelines play a key role in ensuring that the quality of care is maintained, particularly during pandemics, which place enormous pressure on healthcare systems globally. Current national guidelines addressing primary care for COVID-19 demonstrate a focus on providing infection control and minimising the risk of spread in primary care practices while supporting the use of new technology and coordinated partnerships. However, to ensure primary care practice resilience and quality of care are upheld, guidelines must offer recommendations on supply chain management, coordination and operational continuity, supported by adequate resources and robust research into the optimal configuration of services.

\section{Author affiliations}

${ }^{1}$ Dalla Lana School of Public Health, University of Toronto, Toronto, Ontario, Canada ${ }^{2}$ School of Public Health and Health Systems, University of Waterloo, Waterloo, Ontario, Canada

${ }^{3}$ International Care Ministries, Manila, Philippines

${ }^{4}$ Australian National University, Canberra, Australian Capital Territory, Australia ${ }^{5}$ Department of Family and Community Medicine, University of Toronto, Toronto, Ontario, Canada

${ }^{6}$ School of Economics and Management, Guangzhou University of Traditional Chinese Medicine, Guangzhou, Guangdong, China

${ }^{7}$ State Key Laboratory of Respiratory Diseases, The First Affiliated Hospital of Guangzhou Medical College, Guangzhou, China

${ }^{8}$ Nuffield Centre for International Health and Development, Leeds Institute of Health Sciences, University of Leeds, Leeds, UK

Contributors VH designed the search strategy with input from XW. VH, ZZ and RFA carried out the literature searches and screening and discussed discrepancies with XW. VH, ZZ and RFA carried out the extraction. VH wrote the first draft of the review with input from XW, WD, LLL, MRK, KR, GZ, CZ and REGU.

Funding This work was funded by the Canadian Institute of Health Research (CIHR) and the International Research and Development Agency (IDRC) (439835).

Competing interests None declared.

Patient consent for publication Not required.

Provenance and peer review Not commissioned; externally peer reviewed.

Data availability statement All data relevant to the study are included in the article or uploaded as supplemental information.

Supplemental material This content has been supplied by the author(s). It has not been vetted by BMJ Publishing Group Limited (BMJ) and may not have been peer-reviewed. Any opinions or recommendations discussed are solely those of the author(s) and are not endorsed by BMJ. BMJ disclaims all liability and responsibility arising from any reliance placed on the content. Where the content includes any translated material, BMJ does not warrant the accuracy and reliability of the translations (including but not limited to local regulations, clinical guidelines, terminology, drug names and drug dosages), and is not responsible for any error and/or omissions arising from translation and adaptation or otherwise.

Open access This is an open access article distributed in accordance with the Creative Commons Attribution Non Commercial (CC BY-NC 4.0) license, which permits others to distribute, remix, adapt, build upon this work non-commercially, and license their derivative works on different terms, provided the original work is properly cited, appropriate credit is given, any changes made indicated, and the use is non-commercial. See: http://creativecommons.org/licenses/by-nc/4.0/.

ORCID iD

Xiaolin Wei http://orcid.org/0000-0002-3076-2650

\section{REFERENCES}

1 Starfield B, Shi L, Macinko J. Contribution of primary care to health systems and health. Milbank Q 2005;83:457-502.

2 World Health Organization. Declaration of Astana [Internet. Geneva: World Health Organization, 2018. https://www.who.int/docs/defaultsource/primary-health/declaration/gcphc-declaration.pdf?ua $=1$

3 World Health Organization. Declaration of Alma-Ata International Conference on primary health care development. , 1978: 47, 159-61.

4 United Nations. Political Declarationof the High-level Meeting on Universal Health Coverage "Universal health coverage: moving together to build a healthier world" [Internet]. New York, 2019. Available: https://www.un.org/pga/73/wp-content/uploads/sites/53/ 2019/07/FINAL-draft-UHC-Political-Declaration.pdf [Accessed 28 Aug 2020]. 
5 Yang X, Yu Y, Xu J, et al. Clinical course and outcomes of critically ill patients with SARS-CoV-2 pneumonia in Wuhan, China: a singlecentered, retrospective, observational study. Lancet Respir Med 2020;8:475-81.

6 Kunin M, Engelhard D, Thomas S, et al. Challenges of the pandemic response in primary care during Pre-Vaccination period: a qualitative study. Isr J Health Policy Res 2015;4:32.

7 Rust G, Melbourne M, Truman BI, et al. Role of the primary care safety net in pandemic influenza. Am J Public Health 2009;99 Suppl 2:S316-23.

8 Wynn A, Moore KM. Integration of primary health care and public health during a public health emergency. Am J Public Health 2012;102:e9-12.

9 World Health Organization, UNICEF. A vision for primary health care in the 21st century: towards universal health coverage and the sustainable development goals, 2018. Available: https://apps.who. int/iris/handle/10665/328065 [Accessed 20 Apr 2020].

10 Woolf SH, Grol R, Hutchinson A, et al. Clinical guidelines: potential benefits, limitations, and harms of clinical guidelines. BMJ 1999;318:527-30.

11 Tricco AC, Langlois EV, Straus SE. Rapid reviews to strengthen health policy and systems: a practical guide, 2017.

12 Bowen GA. Document analysis as a qualitative research method. Qualitative Research J 2009;9:27-40.

13 Patel MS, Phillips CB, Pearce C, et al. General practice and pandemic influenza: a framework for planning and comparison of plans in five countries. PLoS One 2008;3:e2269.

14 Hsieh H-F, Shannon SE. Three approaches to qualitative content analysis. Qual Health Res 2005;15:1277-88.

15 Gale NK, Heath G, Cameron E, et al. Using the framework method for the analysis of qualitative data in multi-disciplinary health research. BMC Med Res Methodol 2013;13:117.

16 Republic of the Philippines Department of Health. Interim Guidance on Healthcare Provider Networks [Internet], 2020. Available: https:// www.doh.gov.ph/sites/default/files/health-update/dm2020-0178.pdf [Accessed 21 Apr 2020].

17 NHS England. Guidance and standard operating procedures General practice in the context of coronavirus (COVID-19) [Internet], 2020 Available: https://www.england.nhs.uk/coronavirus/wp-content/ uploads/sites/52/2020/03/C0133-COVID-19-Primary-Care-SOP-GPpractice_V2.1_6-April.pdf [Accessed 21 Apr 2020].

18 National Health Commission. Guidelines for the diagnosis and treatment of COVID-19. China. Trial Version 7, 2020.

19 National Health Commission. Implementation plan for COVID-19 prevention and control. China. Trial Version 6, 2020.

20 CDC. Outpatient and Ambulatory Care Settings: Responding to Community Transmission of COVID-19 in the United States [Internet]. Centers for Disease Control and Prevention, 2020. Available: https:// www.cdc.gov/coronavirus/2019-ncov/hcp/ambulatory-care-settings. html [Accessed 21 Apr 2020]

21 Ethiopian Public Health Institute. National comprehensive COVID19 management Handbook. 162. First ed, 2020.

22 Public Health Agency of Canada. COVID-19 Pandemic Guidance for the Health Care Sector [Internet], 2020. Available: https:// www.canada.ca/en/public-health/services/diseases/2019-novelcoronavirus-infection/health-professionals/covid-19-pandemicguidance-health-care-sector.html\#a42 [Accessed 21 Apr 2020].

23 Ministry of Health New Zealand. Updated advice for health professionals: novel coronavirus (COVID-19) [Internet]. Ministry of Health New Zealand, 2020. Available: https://www.health.govt. nz/system/files/documents/pages/updated-advice-for-healthprofessionals-covid-19-16-aprilv3.pdf [Accessed 21 Apr 2020]

24 Ministry of Health Sri Lanka. COVID-19 (New Coronavirus) Outbreak in Sri Lanka Interim Guidelines for Sri Lankan Primary Care Physicians Version 3.1 [Internet], 2020. Available: http://www.epid. gov.lk/web/index.php?option=com_content\&view=article\&id=131: topics-recent\&ltemid=487\&lang=en [Accessed 21 Apr 2020].

25 Ministry of Health Malaysia. Screening and triaging [Internet], 2020. Available: http://www.moh.gov.my/moh/resources/Penerbitan/ Garis\%20Panduan/COVID19/Annex_2c_Screening_Triaging 22032020.pdf [Accessed 21 Apr 2020].

26 Nigeria Centre for Disease Control. National Interim Guidelines for Clinical Management of COVID-19 [Internet], 2020. Available: https:// ncdc.gov.ng/themes/common/docs/protocols/177_1584210847.pdf [Accessed 21 Apr 2020].

27 Ministry of Health \& Family Welfare Government of India. COVID-19 Book of Five Response and Containment Measures for ANM, ASHA, AWW [Internet], 2020. Available: https://www.mohfw.gov.in/pdf/ 3Pocketbookof5_Covid19_27March.pdf [Accessed 22 Apr 2020].

28 Ministry of Health Malaysia. Management of PUI as outpatient [Internet], 2020. Available: http://www.moh.gov.my/moh/resources/
Penerbitan/Garis\%20Panduan/COVID19/Annex_2a_PUI_not_ admitted_22032020.pdf [Accessed 21 Apr 2020].

29 Public Health Agency of Canada. Coronavirus disease (COVID-19): For health professionals [Internet]. aem, 2020. Available: https:// www.canada.ca/en/public-health/services/diseases/2019-novelcoronavirus-infection/health-professionals.html [Accessed $21 \mathrm{Apr}$ 2020].

30 Australian Government Department of Health. Coronavirus Disease 2019 (COVID-19) CDNA National Guidelines for Public Health Units [Internet], 2020. Available: https://www1.health.gov.au/internet/ main/publishing.nsf/Content/7A8654A8CB144F5FCA2584F8 001F91E2/\$File/interim-COVID-19-SoNG-v2.7.pdf [Accessed 24 Apr 2020].

31 Cormican M. V3.0 Preliminary Guidance on Minimising Risk of Transmission of Respiratory Virus in GP Practice update 3/4/2020 [Internet]. Ireland: Health Protection Surveillance Centre, 2020. Available: https://www.hpsc.ie/a-z/respiratory/coronavirus/ novelcoronavirus/guidance/primarycareguidance/adviceriskassess mentandmanagementofpatients/V3.0-Prelim-Guidance-MinimisingRisk-of-Transmission-of-Respiratory-Virus-in-GP-Practice-Update\% 2003-04-2020-MC1 [Accessed 21 Apr 2020].

32 Department of Health Republic of South Africa. Clinical management of suspected or confirmed COVID-19 disease version 3 (27th March 2020. National Institute for Communicable Diseases, 2020.

33 Nigeria Centre for Disease Control. Infection prevention and control recommendations during health care when COVID-19 is suspected [Internet], 2020. Available: https://ncdc.gov.ng/themes/common/ docs/protocols/172_1583044210.pdf [Accessed 22 Apr 2020].

$34 \mathrm{NHS}$ England. Social prescribing [Internet]. Available: https://www. england.nhs.uk/personalisedcare/social-prescribing/ [Accessed 28 Apr 2020].

35 Australian Government Department of Health. COVID-19 National Health Plan - Primary Care - Bulk Billed MBS Telehealth Services [Internet]. Australian Government Department of Health, 2020. Available: https://www.health.gov.au/resources/publications/covid19-national-health-plan-primary-care-bulk-billed-mbs-telehealthservices [Accessed 22 Mar 2020].

36 Makri A. Bridging the digital divide in health care. Lancet Digit Health 2019;1:e204-5

37 DeClerq C. Telehealth back up and running after technical issue shut system down. Toronto [Internet], 2020. Available: https://toronto. ctvnews.ca/telehealth-back-up-and-running-after-technical-issueshut-system-down-1.4858173 [Accessed 22 Mar 2020].

38 Ang HM. COVID-19 outbreak: What you need to know about the Public Health Preparedness Clinics [Internet]. CNA, 2020. Available: https://www.channelnewsasia.com/news/singapore/covid-19-phpcpublic-health-clinic-need-to-know-subsidies-where-12441664 [Accessed 24 Apr 2020].

39 Australian Government Department of Health. COVID-19 National Health Plan - Primary Health - Respiratory Clinics [Internet] Australian Government Department of Health, 2020. Available: https://www.health.gov.au/resources/publications/covid-19-nationalhealth-plan-primary-health-respiratory-clinics [Accessed $22 \mathrm{Mar}$ 2020].

40 Smith F. Private local pharmacies in low- and middle-income countries: a review of interventions to enhance their role in public health. Trop Med Int Health 2009;14:362-72.

41 Sinanovic E, Kumaranayake L. Quality of tuberculosis care provided in different models of public-private partnership in South Africa. Report no: ID 992780. Rochester, NY: Social Science Research Network, 2007. https://papers.ssrn.com/abstract $=992780$

42 Abramson J, Kark S. Community Oriented Primary Care: Meaning and Scope [Internet]. In: Connor E, Mullan F, eds. Community oriented primary care: new directions for health services delivery. National Academies Press (US), 1983.

43 Paige S, Jones M, D'Ambrosio L, et al. Strengthening community partnerships with local public health through regional pandemic influenza exercises. Public Health Rep 2010;125:488-93.

44 Duff JF, Buckingham WW. Strengthening of partnerships between the public sector and faith-based groups. Lancet 2015;386:1786-94.

45 Lee S, Lau L, Lim K. The Presence of Cough and Tuberculosis: Active Case Finding Outcomes in the Philippines [Internet]. Vol. 2019, Tuberculosis Research and Treatment. Hindawi, 2019. Available: https://www.hindawi.com/journals/trt/2019/4578329/ [Accessed 25 Mar 2020].

$46 \mathrm{Ng} \mathrm{K}$, Poon BH, Kiat Puar TH, et al. COVID-19 and the risk to health care workers: a case report. Ann Intern Med 2020.

47 Amelia N. Where Are All the Face Masks for Coronavirus? - The New York Times, 2020. Available: https://www.nytimes.com/article/facemasks-coronavirus.html [Accessed 22 Mar 2020]. 
48 Yang L, Huang C, Liu C. Distribution of essential medicines to primary care institutions in Hubei of China: effects of centralized procurement arrangements. BMC Health Serv Res 2017;17:727.

49 Kuupiel D, Tlou B, Bawontuo V, et al. Poor supply chain management and stock-outs of point-of-care diagnostic tests in upper East region's primary healthcare clinics, Ghana. PLoS One 2019;14:e0211498.

50 Nieva RF. Assessment of medicines supply chain management of select primary care facilities in the Philippines. Pharmaceutical Sciences Asia 2019;46:231-7. 